\title{
Frequency of Associated Factors Causing Dental Caries in Patients Reporting at Tertiary Care Hospital
}

\author{
Zain Abid Khan ${ }^{1}$ \\ Beenish Qureshi ${ }^{2}$ \\ Usman Anwer ${ }^{3}$ \\ Syeda Kinza Asghar ${ }^{4}$ \\ Kaneeza Fatima ${ }^{5}$ \\ BDS \\ BDS, FCPS \\ BDS, FCPS \\ BDS \\ BDS
}

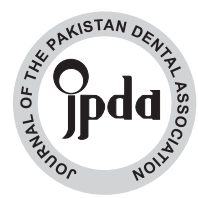

OBJECTIVE: The objective of this study was to determine the dental caries experience and the frequency of the associated factors causing dental caries.

METHODOLOGY: This was a cross-sectional study conducted in Islamabad Dental Hospital among adults for duration of 3 months. A sample size of 349 patients was selected using convenience sampling. Informed consent was obtained from each patient and associated factors were recorded in a proforma. Clinical examination of each patient was carried out and decayed, missing and filled teeth were recorded in a DMFT chart. Data was analyzed using SPSS version 22.0 and was presented in the form of percentages.

RESULTS: Results showed that the percentage of patients having decayed teeth was $89.4 \%$. Mean DMFT index was 3.56 . It was also observed that $61.6 \%$ of the patients cleaned their teeth daily, among which $58.8 \%$ cleaned their teeth once a day and only $10.2 \%$ cleaned twice a day. Tooth brush was used by $78.4 \%$ of the patients, whereas majority of the patients did not use any cleaning aid such as tooth pick or floss. It was also observed that $72.2 \%$ of the patients consumed sweets once a day, while $90.8 \%$ didn't brush their teeth after sweet intake.

CONCLUSION: Poor oral hygiene practices and improper dietary habits are observed among majority of the participants in the study. Oral health education programs could be used to educate the masses regarding oral hygiene practices and dietary controls.

KEY WORDS: Dental caries, Associated risk factors, Oral hygiene, DMFT.

HOW TO CITE: Khan ZA, Qureshi B, Anwer U, Asghar Sk, Fatima K. Frequency of associated factors causing dental caries in patients reporting at tertiary care hospital. J Pak Dent Assoc 2019;28(3):118-121.

DOI: https://doi.org/10.25301/JPDA.283.118

Received: 08 February 2019, Accepted: 17 June 2019

\section{INTRODUCTION}

$\mathrm{D}$ Dental caries is considered to be one of the most prevalent and chronic oral disease. ${ }^{1}$ It is an infectious microbial disease of the teeth that results in localized dissolution and destruction of the calcified tissues often resulting in cavitation. ${ }^{2}$

Consequences of dental caries include pain, discomfort, eating difficulty, tooth loss, bacteremia, malocclusion and lower self-esteem. ${ }^{3}$ Moreover, it can have financial burden

1. PG Resident, Department of Operative Dentistry, Islamabad Medical \& Dental College, Bhara Kahu.

2. Associate Professor, Department of Operative Dentistry, Islamabad Medical \& Dental College, Bhara Kahu.

3. Assistant Professor, Department of Operative Dentistry, Islamabad Medical \& Dental College, Bhara Kahu.

4. House Officer, Islamabad Medical \& DentalCollege, Bhara Kahu.

5. House Officer, Islamabad Medical \& DentalCollege, Bhara Kahu.

Corresponding author: "Dr. Zain Abid Khan"<zain.khan316336@gmail.com > on the individual and families as millions of dollars are being spent worldwide every year to manage pain and discomfort. ${ }^{4}$

Certain risk factors are associated with prevalence of dental caries and they play a significant role in the disease process. These factors include socioeconomic status, age, gender, brushing habit, dietary habit, xerostomia due to medications or Sjogren's syndrome, patient education and attitude towards oral hygiene and access to dental services. ${ }^{5}$ Early education in dental care is critical among children. Tooth brushing technique, flossing and proper dietary habits are necessary contributors for good hygiene practice. Lower socioeconomic status carries significant caries rate because of poor oral hygiene practices, malnutrition and lack of awareness. ${ }^{6}$ Frequent sweet intake, dryness of mouth, and poor oral hygiene increase the likelihood of caries. ${ }^{1}$ Dental caries has been the focus of interest of many 
epidemiological researches conducted worldwide. ${ }^{7}$ There has been a substantial reduction in prevalence of dental caries in developed countries due to the fact that they have improved living conditions and life styles and there are oral health programs being conducted on a large scale. ${ }^{8}$ In Asia the prevalence of dental caries among school going children is 60 to $90 \%{ }^{8}$ Prevalence of dental caries is considerably high in developing countries like Pakistan ${ }^{9,10}$ but there is a scarcity of such epidemiological studies. The epidemiologic surveys are essential for the knowledge of the prevalence of oral diseases and for evaluation of the treatment needs. Therefore, in order to provide optimum preventive and treatment care, it is imperative to have knowledge of the frequency of the associated factors causing dental caries. ${ }^{11}$

The aim of this study was to determine the dental caries experience and frequency of risk factors associated with dental caries.

\section{METHODOLOGY}

This was a cross-sectional study, conducted in the Outpatient department at Islamabad Dental Hospital for the duration of 3 months from November 2017 till January 2018 after the approval from ethical review committee of Islamabad Dental Hospital. Sample size was calculated using WHO sample size calculator ${ }^{12}$ with confidence level $95 \%$, margin of error 5\% and population proportion $65 \%$. A total of 349 patients were recruited in the study via convenience sampling. Patients aged 12 or above and having 16 or more permanent teeth in oral cavity were included in the study. Mentally and physically handicapped patients were excluded.

Informed consent was taken from each patient. Associated factors were recorded using proforma, which included demographic data (such as age and gender) and questions regarding brushing frequency, brushing technique, brushing tool, use of adjunct cleaning aids (Tooth pick, Floss, Mouthwash), frequency of sweets, consumption of snacks in between meals, frequency of brushing after sweet intake and frequency of carbohydrate drink consumption. Clinical examination was performed using dental mirror, explorer and proper illumination. Decayed, missing and filled teeth were recorded in a DMFT chart.

Data was analyzed using SPSS 22. Frequencies of associated factors causing dental caries were assessed and presented in the form of percentages.

\section{RESULTS}

A total of 349 patients were examined, of which 165 $(47.3 \%)$ were males and 184 (52.7\%) were females. Mean age of the patients was 37.15 years with a standard deviation of 14.70. Frequencies of associated factors are shown in table 1 . The responses recorded in the questionnaires showed that $89.1 \%$ of the patients cleaned their teeth, among which $61.6 \%$ cleaned their teeth daily. Most (58.8\%) of the patients brushed their teeth once a day. Tooth brush was used for

\begin{tabular}{|c|c|}
\hline Teeth cleaning & Frequency \\
\hline yes & $311(89.1 \%)$ \\
\hline no & $38(10.9 \%)$ \\
\hline Teeth cleaning per day & Frequency \\
\hline once & $183(58.8 \%)$ \\
\hline twice & $32(10.2 \%)$ \\
\hline more than twice & $4(1.2 \%)$ \\
\hline none & $92(29.5 \%)$ \\
\hline Tool for cleaning & Frequency \\
\hline tooth brush & $244(78.4 \%)$ \\
\hline miswak & $49(15.7 \%)$ \\
\hline others & $18(5.7 \%)$ \\
\hline Tooth Brushing Technique & Frequency \\
\hline bass & $74(23.7 \%)$ \\
\hline modified bass & $10(3.2 \%)$ \\
\hline scrub brush & $192(61.7 \%)$ \\
\hline none & $35(11.2 \%)$ \\
\hline Other cleaning aids & Frequency \\
\hline floss & $6(1.7 \%)$ \\
\hline tooth pick & $66(18.9 \%)$ \\
\hline mouthwash & $6(1.7 \%)$ \\
\hline none & $271(77.7 \%)$ \\
\hline Frequency of sweets per day & Frequency \\
\hline once & $252(72.2 \%)$ \\
\hline twice & $20(5.7 \%)$ \\
\hline more than twice & $16(4.6 \%)$ \\
\hline none & $61(17.5 \%)$ \\
\hline Snacks in between meals & Frequency \\
\hline Yes & $191(54.7 \%)$ \\
\hline No & $158(45.3 \%)$ \\
\hline $\begin{array}{l}\text { Teeth cleaning after sweet } \\
\text { intake }\end{array}$ & Frequency \\
\hline Yes & $32(9.2 \%)$ \\
\hline No & 317 (90.8\%) \\
\hline $\begin{array}{l}\text { Drinking of sweetened } \\
\text { carbonated drinks }\end{array}$ & Frequency \\
\hline Yes & $194(55.6 \%)$ \\
\hline No & 155 (44.4\%) \\
\hline
\end{tabular}

Table 1: Frequency of the associated factors

cleaning by $78.4 \%$ of the patients. Majority $(77.7 \%)$ of the patients did not use any adjunct cleaning aid. Scrub brush technique was used by $61.7 \%$ of the patients for cleaning. 
Majority $(72.2 \%)$ of the patients consumed sweets once a day. Most $(54.7 \%)$ of the patients consumed snacks in between meals.

Frequencies of decayed, missing and filled teeth are shown in table 2 . Results revealed that $89.4 \%$ patients had decayed teeth and the mean DMFT score was 3.56.

\begin{tabular}{|l|l|}
\hline Decayed Teeth & Frequency \\
\hline $\begin{array}{l}\text { Yes } \\
\text { No }\end{array}$ & $312(89.4 \%)$ \\
& \\
\hline Missing Teeth & Frequency \\
\hline $\begin{array}{l}\text { Yes } \\
\text { No }\end{array}$ & $127(36.4 \%)$ \\
& $222(63.6 \%)$ \\
\hline Filled teeth & Frequency \\
\hline Yes & $23(6.6 \%)$ \\
No & $326(93.4 \%)$ \\
\hline
\end{tabular}

Table 2: Frequency of decayed, missing and filled teeth

\section{DISCUSSION}

Dental caries is widespread and one of the most prevalent disease especially in developing countries. There are various biological and social risk factors associated with dental caries including oral hygiene, brushing habits and dietary habits. Epidemiological surveys are required to determine the frequency of these risk factors and hence provide optimum preventive and treatment care.

Oral health behavior and hygiene practices significantly impact one's life and well-being. ${ }^{13}$ Current study reveals that the majority of the patients $(58.8 \%)$ cleaned their teeth once a day. This is in accordance with a study conducted by Prakash et al in which $70 \%$ of the patients cleaned their teeth once a day and only $29.4 \%$ cleaned twice a day. ${ }^{3}$ However, in another study by Kaur et al in Kuala Lumpur, the percentage of patients brushing twice a day was $75.3 \%{ }^{6}$ Tooth brush was used by majority of the patients in the current study and $61.7 \%$ used scrub brushing method for cleaning. Only 3.2\% used modified bass method for cleaning. Modified bass method is considered the brushing technique of choice ${ }^{14}$ and very low percentage of patients using this method to brush their teeth could increase the prevalence of caries. In the current study, majority of the patients did not use any cleaning aid like tooth pick, floss or mouthwash. In a study it was revealed that $67 \%$ of the participants used floss as cleaning aid and most of them were caries free. ${ }^{6}$ Majority of the patients in the current study did not use other cleaning aids and they could be at increased risk of caries. Lack of oral health awareness programs in our society might be the causative factor of these poor oral hygiene practices.
In the present study, $72.2 \%$ of the patients consumed sugar at least once a day. This is in contrast to a study in which majority of the participants consumed sweets more than once a day. ${ }^{4}$ In another study, it was observed that $77 \%$ of the participants consumed sugar once a day, but the researchers found no association between consumption of sugary snacks and dental caries. ${ }^{5}$ In the current study, it was noted that $55.6 \%$ of the patients used sweetened carbonated drink. This is in accordance with a study in which $58.4 \%$ of the participants consumed sweetened beverages, but no association was found between consumption of sweetened beverages and dental caries. ${ }^{5}$ Mulu et al also noted high consumption of sugar (71\%) and sweetened beverages (55\%) among participants in their study, but they found significant association of dental caries with sugary diet. ${ }^{1}$ In the current study, majority of the patients consumed snacks in between meals. This is in accordance with a study in which majority of the patients consumed snacks in between meals. ${ }^{15}$ Results in the present study showed that $90.8 \%$ of the patients did not brush their teeth after sweets intake. In the current study, $89.4 \%$ of the patients had dental caries.

One of the most common methods in oral epidemiology for assessing dental caries prevalence as well as dental treatment needs among populations is decayed, missing and filled index. Higher the DMFT index, higher is the caries rate and poorer is the oral hygiene. DMFT between 2.7 and 4.4 signifies moderate prevalence of caries, high prevalence when DMFT is between 4.5 and 6.5 and very high prevalence when DMFT is greater than or equal to $6.6 .{ }^{16}$ Mean DMFT index recorded in the current study was 3.56 . This is in accordance with a study conducted on adolescents and young adults in Mexico, in which mean DMFT index was 3.48. ${ }^{17}$ Another study conducted in Brazil involving young adults revealed an increased DMFT index of $4.5 .{ }^{18} \mathrm{~A}$ study conducted in Karachi compared the prevalence of dental caries between urban and rural population. High prevalence of dental caries was reported with mean DMFT of 4.95 and 4.93 for urban and rural population respectively. ${ }^{19}$

Current study focused on finding out the frequency of associated factors causing dental caries.

\section{CONCLUSION}

The results of this study indicate a high percentage of patients with dental caries (89.4\%) reporting at Islamabad Dental Hospital. Improper oral hygiene practices are observed as most of the patients brush only once a day and do not use any adjunct cleaning aids. Poor dietary habits are also noted with frequent use of snacks in between mealsand high consumption of carbonated beverages. 


\section{CONFLICT OF INTEREST}

None declared

\section{REFERENCES}

1. Mulu W, Demilie T, Yimer M, Meshesha K, Abera B. Dental caries and associated factors among primary school children in Bahir Dar city: a cross-sectional study. BMC Res Notes. 2014 23;7:949. https://doi.org/10.1186/1756-0500-7-949

2. Bhatia HP, Srivastava B, Khatri S, Aggarwal A, Singh AK, Gupta N. Prevalence of dental caries among 3-15 old school children in Ghaziabad city and its adjoining areas-A correlated survey. J Oral Health Community Dent. 2012;6:135-39.

3. Prakash P, Subramaniam P, Durgesh BH, Konde S. Prevalence of early childhood caries and associated risk factors in preschool children of urban Bangalore, India: A cross-sectional study. Eur J Dent. 2012;6:141-52.

4. Akbar I, Baig MN, Qureshi B, Aziz TA, Osama A, Al Garni HM, Al Onazi ME, Al Khamis AH, Al Sharari E, Al Zarea MO. Frequency of dental caries and associated risk factors in patients attending college of dentistry, Aljouf university-Saudi arabia. Pak Oral Dent J. 2015 1;35:670-74.

5. Hashizume LN, Shinada K, Kawaguchi Y. Factors associated with prevalence of dental caries in Brazilian school children residing in Japan. J Oral Sci. 2011;53:307-12.

https://doi.org/10.2334/josnusd.53.307

6. Kaur S, Maykanathan D, Lyn NK. Factors associated with dental caries among selected urban school children in Kuala Lumpur, Malaysia. Arch Orofac Sci. 2015;10:24-33.

7. Reddy KS, Reddy S, Balaji PK, Reddy H, Reddy A. Prevalence of dental caries among 6-12 years school children of Mahbubnagar District, Telangana State, India: A Cross sectional Study. Indian J Dent Sci. 2017;9:1-7.

https://doi.org/10.4103/0976-4003.201641

8. Sahito N, Sahito MA, Fazlani KA. Prevalence of dental caries among school children in Hyderabad Pakistan. Int J Appl Sci Res Rev. 2015;26:34-8.

9. Amin M, Amanullah BM, Tarar AM. Dental Caries, Periodontal Disease and their Associated Factors Among Patients Visiting Dental Teaching Hospital in Multan, Pakistan. J Pak Dent Assoc. 2016;25:98102.

10. Kazi AQS, Iqbal W, Shaikh SS. Prevalence of Dental Caries. The Professional Med J. 2014;21:750-54.

11. Castro C, Bruzamolin CD, Duda JG, Brancher JA, Pizzatto E. Epidemiological study to determine factors associated with dental caries in schoolers. Revista Sul-Brasileira de Odontologia. 2015;12:28996.

12. Lemeshow S, Hosmer DW, Klar J, Lwanga SK. Adequacy of sample size in health studies. WHO; 19901.

https://apps.who.int/iris/bitstream/handle/10665/41607/047192517 9_eng.pdf

13. Diet, nutrition, and the prevention of chronic diseases: report of a joint WHO/FAO expert consultation. WHO; 200322.

14. Poyato-Ferrera M, Segura-Egea JJ, Bullón-Fernández P. Comparison of modified Bass technique with normal toothbrushing practices for efficacy in supragingival plaque removal. Int. J. Dent. Hyg.. 2003;1:11014.

https://doi.org/10.1034/j.1601-5037.2003.00018.x

15. Mannaa A, Carlén A, Lingström P. Dental caries and associated factors in mothers and their preschool and school children-A crosssectional study. J Dent Sci. 2013 1;8:101-18.

https://doi.org/10.1016/j.jds.2012.12.009

16. Cypriano S, Sousa MD, Wada RS. Evaluation of simplified DMFT indices in epidemiological surveys of dental caries. Rev. Salud Pública. 2005;39:285-92.

https://doi.org/10.1590/S0034-89102005000200021

17. García-Cortés JO, Medina-Solís CE, Loyola-Rodriguez JP, MejíaCruz JA, Medina-Cerda et al. Dental caries' experience, prevalence and severity in Mexican adolescents and young adults. Rev. Salud Pública. 2009;11:82-91.

https://doi.org/10.1590/S0124-00642009000100009

18. Gushi LL, Soares Mda C, Forni TI, Vieira V, Wada RS, de Sousa Mda L. Dental caries in 15-to-19-year-old adolescents in Sao Paulo State, Brazil, 2002. Cad Saude Publica 2005; 21:1383-91. https://doi.org/10.1590/S0102-311X2005000500010

19. Siddiqui TM, Wali A, Siddiqui SH, Heyat U, Nadeem M, Shamim M. An Epidemiological Study of Prevalence of Dental Caries and Periodontal Disease among Adults in Deprived Areas-Karachi. J Oral Health Res. 2013;4:3-7. 